\title{
Literacia Mistórica: \\ um desafio para a educação \\ histórica no século XXI
}

Maria Auxiliadora SCHMIDT"

\section{RESUMO}

Fsse artigo pretende realizar uma sistematização do conceito de literacia histórica. Para isto, tomou-se como referência algumas considerações filosóficas sugeridas, entre outros, por Lee, Oakeshoot e Rusen. A idéia de literacia histórica surgiu a partir dos estudos sobre consciência histórica. Conforme Peter Lee tem afirmado, esse conceito é importante para o desenvolvimento de competências históricas, como as interpretação e orientação temporal.

Palaviras-chave: Literacia histórica - Educação Histórica - Cognição histórica.

\section{Assimilações}

A perspectiva da definição e constituição do conceito de Literacia Histórica vem sendo desenvolvida principalmente por LEE $(2005 ; 2006 ; 2008)$ e se integra ao conjunto de investigações e reflexões pertinentes a um campo de estudos denominado Educação Histórica. Segundo Barca (2005), nestes estudos, os investigadores têm centrado a sua atenção nos princípios, fontes, tipologias e estratégias de aprendizagem em Historia, sob o pressuposto de que a intervenção na qualidade das aprendizagens exige um conhecimento sistemático das idéias dos alunos, por parte de quem ensina. A análise destas idéias implica um enquadramento teórico que respeite a natureza do saber histórico e que de refletir-se, do mesmo modo, na aula de História. (p.15).

\footnotetext{
${ }^{1}$ As reflexões acui desenvolvidas fazem parte das investigações que estão sendo desenvolvidas pela autora no contexto do projeto "Ensinar a ler, ensinar a escrever em História", financiado pelo Cnpq e pela Fundação Artucária-PR.

2 PP(IE-LAPEU)tHH-UJPR.dolinha08@uol.com.br
} 
As preocupações da Educação Histórica com as questões relacionadas aos princípios e finalidades do ensino de Historia, não podem ser identificadas com algumas proposições atuais, centradas na problemática da aprendizagem, e que têm como suporte teorias educacionais do tipo "aprender a aprender". Pelo contrário, a adesão da Educação Histórica a essas preocupações, está intrinsecamente articulada à valorizaç̃ão de uma sólida formação na ciência de referência, pois, no caso de professores de História, o conhecimento que têm da disciplina e o modo pelo qual eles vêem sua estrutura interagem com suas estratégias de ensino. Esses professores não apenas apresentam aos alunos os fatos a ser aprendidos, mas ajudam-nos a compreender a natureza complexa da interpretação e da análise histórica e avaliar a relevância dessa matéria para sua vida cotidiana. (Bransford; Brown; Cocking, 2007).

É consenso que as questões relacionadas à aprendizagem histórica e, portanto, ao seu ensino, estão na pauta das discussões de teorias educacionais e, assim, de políticas educacionais, incluídas em debates que evidenciam a crise atual dos processos de escolarização e, portanto, da escola. Estudos já realizados no âmbito do ensino de História, vêm apontando esta crise3.

Um dos elementos que pode ser destacado neste conjunto de investigações e reflexões é o de que há uma crise da escola como instituição. Trata-se de um questionamento da escola cuja função precípua era formar o cidadão - a chamada pedagogia do cidadão. Esta concepção de escola conferia ao ensino de História a finalidade do preparo para a cidadania, e não estaria em acordo com os debates das escolas historiográficas do século XX e nem com as novas demandas da escola de massa.

Há que se destacar que, nesse processo, as formas de escolarização, provocaram um distanciamento entre a História como ciência e sua organização para fins de ensino, constituindo uma espécie de "especialização técnica". Um dos elementos dessa especialização foi o fato de que o aprendizado passou a ser visto como um processo passível de ser dirigido, controlado e essencialmente prescritivo, como, a indicada na proposta de "transposição didática". Segundo Chevallard

\footnotetext{
Refiro-me, por exemplo, aos trabalhos que vêm sendo apresentados e publicados em Anais dos encontros Perspectivas do linsino de História e Pesquisadores do Ensino de História, além de apresentados em simpósios organizados nos encontros regionais e nacionais da ANPUH.

"Sobre o conceito de "transposição didática" ver CHEVALLARD, Yves. La transposiçion didactica. Del saber sábio al saber enseñado. Buenos Aires: Aique, 2000.
} 
(2000), a transposição didática fundamenta-se na perspectiva da aprendizagem baseada no desenvolvimento de habilidades cognitivas universais, cuja referencia é a pedagogia por objetivos e/ou pedagogia das competências.

Nesse contexto, os estudos relacionados ao campo da Educação Históri$\mathrm{ca}$, abrem um diálogo com as teorias educacionais que procuram entender 0 significado dos processos de escolarização, particularmente no que se refere aos processos de ensino e aprendizagem, face ao declínio da escola como instituição com a "função de", para entendê-la como o espaço da experiência (individual e social) dos sujeitos com o conhecimento, na esteira dos estudos desenvolvidos por investigadores como Charlot(2000), Dubet, (2006), Dubet/Martuccelli,(1998). A partir dessas concepções, amplia-se o conceito de "escola" para todo ambiente em que pode ocorrer a relação com o conhecimento. Desse princípio decorrem alguns pressupostos importantes.

Um primeiro pressuposto é o de que o professor (historiador) não pode, em hipótese alguma, ser um mero reprodutor/transmissor, depositador de conhecimentos, mas necessita estabelecer, em sua formação, uma relação orgânica entre ensino e pesquisa. Essa relação não implica em transformar ensino em pesquisa, mas entende que a articulação entre a forma pela qual cada um se pensa como professor e a condição de viver a atividade de professor é produzida historicamente. Neste sentido, é importante que se busque superar a lógica perversa da divisão técnica do trabalho, que separou, historicamente, aqueles professores que são autorizados a produzir conhecimento, daqueles a quem é conferida a sua transmissão.

Outro pressuposto é o da necessidade de se entender a idéia de aluno como uma invenção históricamente determinada. Assim, torna-se fundamental entender as crianças e os jovens como construções históricas, sociais e culturais, entendendo as suas aprendizagens históricas também a partir das condições históricas e objetivas em que eles constroem a si mesmos e, portanto, as suas identidades.

Ainda é importante levar em conta que, no momento em que se fala do "recuo da teoria" (Moraes, 2003), o campo teórico no qual se inscrevem os fundamentos da Educação Histórica, propõe alternativas às críticas que os pós modernos fazem à racionalidade histórica. Segundo Moraes (2003), as ciências sociais foram as que mais sofreram o impacto da crítica pós-moderna, pois 
Procedeu-se a uma verdadeira sanitarização na "racionalidade moderna e iluminista", vertendo-se fora não só as impurézas detectadas pela inspeção crítica, mas o próprio objeto da inspeção; não apenas os métodos empregados para validar o conhecimento sistemático e arrazoado, mas a verdade, o racional, a objetividade, enfim, a própria possibilidade de cognição do real. Instaurou-se, então, um mal-estar epistemológico (...) 0 recuo da teoria foi decorrência natural desse processo.(p.156-157).

Após incorporar a crítica que o pós-modernismo faz ao conhecimento histórico, Rusen (1993;), reafirma que enquanto os seres humanos forem seres humanos, eles necessitarão de uma forma específica de orientação de suas vidas práticas em termos temporais que se realiza na consciência histórica e se expressa na narrativa histórica. Mas, ao contrário do pensamento histórico moderno, que efetua uma conexão genética entre o passado e o presente e faz com que o pensamento histórico dê a impressão de que o passado se move em direção ao presente, esta crítica devolveu ao passado a sua dignidade. Assim, é preciso aceitar que há uma multiplicidade de histórias, e não a História como uma entidade factual. Isto não significa cair no relativismo, por isto necessitamos de uma idéia de unidade da experiência histórica dentro da diversidade de perspectivas históricas, bem como de categorias históricas para pensarmos historicamente.

Desses pressupostos decorre a afinidade eletiva da Educação Histórica com o principio de que a finalidade do ensino de História é a formação da consciência histórica. Apesar de polivalente e polissêmico, o conceito de consciência histórica (ou pensamento histórico) é aqui apreendido a partir de Rusen (2001), para quem ela é o fundamento da ciência da história e pode ser considerada como a soma das operações mentais com as quais os homens interpretam sua experiência de evolução no tempo de seu mundo e de si mesmos, de forma tal que possam orientar, intencionalmente, sua vida prática no tempo. (Rusen, 2001, p.57).

É nesses princípios que reside a necessidade de se abordar a construção de um conceito de literacia histórica, que tem como suporte a idéia de "cognição histórica situada", porque, segundo Lee, a História vem sendo influenciada por

Sobre o conceito de "cognição histórica situada" ver SCHMIDT, M.A. "Cognição histórica situada: que aprendizagem histórica é esta?". In. SCHMIDT, M.A. / BARCA, I. Aprender história: perspectivas da educação históricat. Ijuí: Unijuí, 2009. 
propostas que a tomam responsável em produzir cidadãos bons e críticos e a proposição de uma literacia histórica poderia fornecer elementos diferentes para uma educação histórica e, talvez, atingir objetivos que as propostas anteriores não atingiram, pois, diz o autor, um conceito de literacia histórica demanda ir além disso ao começar a pensar seriamente sobre o tipo de substância que a orientação necessita e o que as compreensões disciplinares devem sustentar naquela orientação". (Lee, 2006, p. 148).

\section{Alguns pressupostos}

A partir das assimilações apresentadas, é válido concluir que a História e seu ensino não podem ser considerados como a aquisição de fatos ou conteúdos que mostrem os acontecimentos da humanidade através dos séculos. Ao contrário, assume-se o pressuposto fundamental de que a História como ciência é uma modalidade específica de conhecimento que, segundo Rusen, emerge da carência de todos os homens, que agem e sofrem as consequências das ações dos outros, de orientar-se em meio às mudanças que experimentam em seu mundo e em si mesmos (Rusen, 2001: p.12).

Assim, são as "carências" de orientação na vida presente que nos colocam em relaçao ao passado e ao futuro. Isso trás como consequiência a possibilidade de que todas as pessoas constroem e tenham uma consciência histórica, a partir de relações que se estabelecem com o passado, tendo como referência o seu presente. Segundo Oakeshott (2003), a vinculação do passado com o presente deve ser feita a partir da distinção entre o que se convencionou chamar "passado prático" e "passado histórico", porque a nossa existência cotidiana comporta referências a múltiplos passados. O passado prático inclui, entre outros, o passado encapsulado (somatória das experiências dos indivíduos que independe da rememoração), 0 passado lembrado (da memória)e o passado consultado (da psicanálise). Existem também os vestígios materiais ou evidências do passado que estão em museus, arquivos, que podem ser denominados de passado registrado, do qual o historiador se vale, por meio do que Marc Bloch chamou de leitura tortuosa, para construir as intrigas da historia, e, portanto, o passado interpelado, ou passado histórico. É importante frisar que, ambos, passado prático e passado histórico. têm em comum o fato de começarem no presente. (Oakeshott, 2003). 
Assim, considerando que não se pode escapar do passado, a literacia histórica baseia-se no entendimento de que se deve propiciar e obter condições para podermos fazer escollhas intencionais a respeito do passado. Por isto, é válida a questão colocada pela literacia histórica, de que é importante saber que passado se quer, que usos a história tem para a vida prática e de que maneira a História pode ser aprendida.

Neste sentido, um conceito de literacia histórica parte do pressuposto de que a História é, como aponta Lee, uma forma pública de conhecimento público que tem desenvolvido princípios para lidar com o passado. Isto não quer dizer que é uma disciplina fixa e acabada, ou que é a única forma de se lidar com 0 passado, ou que são requeridas capacidades esotéricas que só intelectuais muito capazes podem ter tempo e competência para dominar". (2008, p. 13) Mas, como completa este autor, a História é um estudo do passado que tem que seguir alguns critérios, como:

- pensar históricamente pressupõe produzir bons argumentos sobre as questões e pressuposiçoes relacionadas ao passado, apelando à validade da historia e à plausibilidade de suas afirmações;

- pensar historicamente significa aceitarmos que sejamos obrigados a contar historias diferentes daquelas que preferimos contar;

- pensar historicamente significa compreender a importância de se respeitar o passado e tratar as pessoas do passado como elas gostariam de ser tratadas e não saqueando o passado para servir a determinados interesses do presente.

Baseando-se nesses pressupostos e princípios está em curso a constituição de um conceito de literacia histórica, referenciada na própria ciência da Histórica, como completa Lee (2008) - "Se desejamos afirmar que estamos ensinando Historia, em vez de outras formas de pensar acerca do passado, é crucial que os alunos compreendam que existe uma forma de conhecimento de História e que 0 conhecimento do passado não é só uma questão de opinião pessoal" (p.13).

\section{Constituindo o conceito}

A palavra "literacia" é uma experiência ausente nos dicionários de língua portuguesa. Assim, sua conceituação, nesse texto, está restrita à forma pela qual, na 
área da Educação Histórica, ela vem sendo investigada pelos historiadores, em referência a pressupostos teóricos da própria Historia; como alguns já apontados.

Para se chegar a alguns indicativos do que significa ter uma literacia histórica, é importante retomar a idéia de Rusen (2001) de que a aprendizagem histórica advém da necessidade que se tem do desenvolvimento da competência de dar sentido (significado) ao tempo que fica evidenciada quando os sujeitos narram a historia, construindo formas coerentes de comunicação de suas identidades históricas. Neste ponto, aparece um encaminhamento da literacia histórica, qual seja a da necessidade de se desenvolver e trabalhar operações mentais da consciência histórica que desenvolvam a narrativa, porque é somente a partir desta que o conhecimento torna-se consciente, ou autoconhecimento e o sujeito aumenta sua capacidade de ver o passado como passado histórico e não somente como passado prático ou passado morto. Isto porque a aprendizagem histórica só é aprendizagem quando ela muda os padrões de interpretação do passado, o que pressupõe um processo de internalizaçao dialógica e não passiva do conhecimento histórico, além de uma exteriorização para fora, no sentido de mudar a relação com a vida prática e com o outro.

Na esteira das idéias de Rusen, pode-se afirmar que a "competência narrativa" é a expressão da forma, do conteúdo e da função da consciência histórica. O conteúdo é a capacidade de aprender a olhar o passado e vê-lo em sua especificidade temporal, de distanciar-se do passado e diferenciá-lo do presente, reconhecendo nele a sua própria experiência e a mudança Esta capacidade é também chamada "competência da experiência". A forma é a capacidade de se analisar as diferenças de temporalidades entre o passado, o presente e o futuro, por meio da concepção de um todo temporal significativo que abranja todas as dimensões do tempo. Trata-se da "competência de interpretação" que possibilita traduzir as experiências passadas em compreensão do presente e expectativas do futuro. A função é a capacidade que permite a utilização do todo temporal (passado, presente e futuro) como guia de ação na vida diária. Trata-se da competência de orientação.

Uma das condições aludidas por Rusen (2001) diz respeito ao fato de que, a narrativa como constitutiva da consciência histórica recorre a lembranças para interpretar as experiências do tempo. Neste sentido, o passado seria como uma floresta para dentro da qual os homens, pela narrativa histórica, lançam seu 
clamor, a fim de compreenderem, mediante o que dela ecoa, o que lhes é presente sob a forma de experiência do tempo (mais precisaménte: o que mexe com eles) e poderem esperar e projetar um futuro com sentido. (RÜSEN, 2001, p. 63)

Mas não é somente pela lembrança que se recupera o passado. Seja qual for o modo em que a consciência histórica penetra no passado, como no itinerário dos arquivos da memória, o impulso para esse retorno é sempre dado pelas experiências do tempo presente. Ou seja, a consciência histórica é o local em que o passado é levado a falar e este só vem a falar quando questionado; e a questão que o faz falar origina-se da carência de orientação na vida prática atual, diante das suas experiências no tempo. Trata-se de uma lembrança interpretativa que faz presente o passado, no aqui e agora.

Uma segunda condição enunciada por RUSEN (2001) é a "representação de continuidade", que o autor define como a íntima interdependência entre passado, presente e futuro e que serve à orientação da vida humana prática atual. Ou seja, "a narrativa histórica torna presente o passado, de forma que o presente aparece como uma continuação no futuro" (p. 64)

Os critérios determinantes das representações de continuidade formam a terceira condição da narrativa como operação intelectual decisiva para a constituição da consciência histórica. 0 elemento unificador no processo da relação presente, passado, futuro, mediante a narrativa é a resistência do ser humano à perda de si e de seu esforço de auto-afirmação, e se constitui como identidade.

A consciência histórica constitui-se mediante a operação, genérica e elementar da vida prática, do narrar, com o qual os homens orientam seu agir e sofrer no tempo. Mediante a narrativa histórica são formuladas representações de continuidade da evolução temporal dos homens e seu mundo, instituidoras de identidade, por meio da memória, e inseridas, como determinação de sentido, no quadro de orientação da vida prática humana. (RÜSEN, 2001, p. 67)

Os estudos de Husband (2003) também podem ser tomados como referência para a literacia histórica, no que diz respeito à importância da narrativa histórica. Para este autor, diferentemente dos historiadores, os alunos nas escolas não buscam gerar "novo" conhecimento por meio de evidências e narrativas históricas, mas eles geram novas compreensões históricas pessoais. Assim, umas das formas como os alunos e professores conferem significado ao passado é a de pensar acerca da construção de narrativas ou versões deste passado, apreendido, conforme Oakeshott (2003), a partir das relações estabelecidas com o presente. 
Segundo HUSBAND (2003), no ensino de história, o emprego da narrativa em aula e a relação que o aluno estabelece com ela têm sido constantemente associados ao um didatismo ativo do professor e à uma passividade do aluno. Ele chama a atenção para as sobre-simplificações que constantemente professores esboçam acerca dos personagens e contextos históricos, caricaturando-os ou apresentando-os como arquétipos do bem e do mal, e nestas reduções dificultam aos alunos, nas relações que estabelecem com as narrativas já produzidas, incluso a do professor, ou na construção de narrativas, utilizá-las como argumentos e meios para alcançar um fim, ou seja, a construção da compreensão histórica. A narrativa, portanto, não é um fim por si só, mas a sua finalidade é contribuir para gerar compreensão sobre o passado, ativando o pensamento de quem aprende. Desta forma, ela precisa ser explorada em aulas de História, pois narrar significa contar e recontar histórias, "Isto significa contar histórias, mas também pedir aos alunos que as recontem: submetê-las a um exame crítico, criando um sentido ao que chamei de verossimilhança è sua lógica. Envolve uma dúvida construtivamente céptica sobre a natureza das histórias que contamos. Significa relacionar histórias com os princípios organizativos - as idéias de causa, continuidade, mudança - do discurso histórico complexo". (HUSBAND, 2003, p. 39).

Nesta direção, é preciso lembrar a existência de uma relação orgânica entre a competência narrativa e a criação de identidades individuais e coletivas. Esta relação ocorre porque os s sujeitos, por meio da narrativa, são capazes de desenvolver abordagens de si e do outro, e isso exige a consciência de sua própria historicidade e, portanto, de uma consciência histórica. Por outro lado, ao narrarem a sua vida e do outro, ele se inventa e institui seu pertencimento no mundo. Ele se forja pela narrativa, ao criar um sentimento de continuidade no tempo e um sentimento de coerência interna, que lhe permite se interpretar narrativamente, como sendo um sujeito singular, porém, matizado por elementos sociais e culturais.

A partir destas considerações, pode-se caracterizar a literacia histórica como a construção de sujeitos historicamente letrados, que sejam minimamente capazes de, segundo Lee (2008) realizar algumas coisas, como:

- ter uma imagem do passado que lhes permita orientarem-se no tempo, a qual exige o domínio de determinados conteúdos históricos ou uma compreensão substantiva coerente do passado; 
- um conhecimento de como desenvolver uma explicação e narrativa do passado, o que pressupõe o domínio de idéias substantivas e de idéias de segunda ordem que colaborem para organizar o passado, fazendo com que o conhecimento do passado seja possível;

Como afirma Lee (2008), "se os estudantes são capazes de dar sentido ao passado e adquirirem algum conhecimento do que podemos dizer acerca dele e, simultaneamente, serem capazes de utilizar esse conhecimento de modo a que tenha claramente uma utilidade/aplicabilidade, talvez possa se afirmar que os estudantes são historicamente letrados".

\section{Primeiras conclusões}

Se o século XIX foi o século da História e da paixão pela História, podese afirmar que o século XX foi o século dos usos públicos da história. Além da difusão de propostas curriculares e manuais didáticos que acompanharam 0 processo de massificação da escolarização, a Historia foi manipulada para fins políticos e também ocupou lugar na mídia, tornando-se um lucrativo produto da industria cultural.

No entanto, no século XXI, ainda enfrenta o sério desafio de elucidar o que pensar acerca de questões como "para que serve ensinar historia?, que historia ensinar? o que é aprender história?

De modo geral, seja nos critérios de avaliações de manuais didáticos, seja nas orientações de propostas curriculares, as lacunas em relação a uma concepção de literacia histórica tem provocado o "seqüestro da cognição histórica" (Schmidt/ Garcia,2007). O uso desse conceito encontra referência nos trabalhos de Faria e Meneghetti (2001), que analisam a ação do atual modelo de produção e sua capacidade de "seqüestrar a subjetividade do trabalhador estabelecer mecanismos de controle psicológico, subsumindo-o à lógica do capital". A perspectiva desses autores não valida a possibilidade de se compreender os sujeitos como agentes. Assim, a subjetividade - ou usando a expressão empregada por Dubet (1996), A consciência que os sujeitos têm do mundo e deles próprios, pode ser capturada ou seqüestrada, restringindo, mas não impedindo, processos de susbjetivaçao, pelos quais o sujeito se representa e age como um sujeito crítico, confrontado com uma determinada sociedade e sistema de produção e dominação. 
Entende-se que é possível, por homologia, pensar que a relação entre a concepção de aprendizagem e o método de ensino, que tem subsidiado a os processos de escolarização da História, particularmente em suas propostas e usos públicos, têm agido no sentido de seqüiestrar a cognição histórica dos alunos, quando estabelecem formas de ensinar e aprender que restringem, mas não invalidam, as possibilidades de formação de uma contraconsciência histórica. Neste sentido, recorre-se às reflexões do escritor Cláudio Magris (cujo livro Às Cegas foi premiado na ultima feira do livro de Frankfurt), quando afirma que

A grande mudança (do século XXI) foi o fato de que hoje, pela primeira vez na História, temos a sensação física, concreta, ora excitante ora estimulante, ora inquietante ora estarrecedora, de que estamos envolvidos no mundo e de que, em todos os nossos atos, envolvemos o mundo inteiro. Não podemos mais considerar - e este é um progresso - nada nem ninguém, nenhum país e nenhum povo, como algo distante que não tem nada a ver conosco. Tudo isto comporta mudanças enormes; enormes esperanças e enormes perigos. Pela primeira vez, vivemos concretamente uma época universal, mas com um sentimento de profunda ameaça. (Magris, 2009, p. 6).

Tendo em vista as reflexões apresentadas, ao aceitarmos os desafios já impostos pelo século XXI, a literacia histórica assume que sua finalidade é a formação da consciência histórica, tendo como referência a construção, não de uma relação prática ou morta com o passado, mas uma relação histórica cada vez mais complexa, em que a consciência histórica seja portadora da orientação entre o presente, o passado e o futuro, no sentido do voltar-se para dentro ( 0 papel das identidades) e para fora (na perspectiva da alteridade). Ao pensar a relação com o conhecimento histórico e, portanto, o ensino e a aprendizagem da História como a internalização de determinada consciência histórica pelos sujeitos, pode-se falar em internalizar para manter e conservar ou subjetivação, isto é, interiorização mais ação dos sujeitos, com vistas às intervenções e transformações na vida prática.

Como disse Magris (2009), estamos envolvidos no mundo e nossos atos envolvem o mundo inteiro, de forma inquietante e estarrecedora. Este envolvimento pressupõe admitir, conforme propõe Moraes (2003) a possibilidade de transgredir; 
não a transgressão individualista, na esfera da liberdade privada, mas aquela que guarda em si a polaridade entre uma certa universalidade reconhecida e o que fazemos de nossa liberdade. (Moraes,2003, p. 158).

\section{Referências}

BARCA, Isabel. Educaçao Histórica: Uma nova área de investigação. In. ARIAS, José Miguel. (org). Dez Anos de pesquisas em ensino de Historia. Londrina: AtritoArt, 2005.

CHARLO'T, Bernard. Da relaçao com o saber. Porto Alegre: Artmed, 2000.

BRANSFORD, A./ BROWN, A.L./ COCKING, R.R. Como as pessoas aprendem. Cérebro, mente, experiência e escola. São Paulo: Senac, 2007.

DUBET, Franç̧ois. El declive de la institución. Barcelona: Gedisa, 2006.

DUBET, F.MARTUCCELLI, Danilo. Em la escuela. Sociologia de la experiência escolar. Madrid: Losada, 1998.

FARIA, J.H./ MENEGHETTI, F.K. O seqüestro da subjetividade e as novas formas de controle psicológico no trabalho: uma abordagem crítica ao modelo toyotista de produção. In. ENAMPAD, 2001, Campinas.

LEE, Peter. Educaçao Histórica, consciência histórica e literacia histórica. In.BARCA, I.(org.) Estudos de consciência histórica na Europa, América, Ásia e África. Braga: Uminho, 2008.

LEE, Peter. Em direção a um conceito de literacia histórica. In Revista Educar. Dossiê Educaçao Histórica. Curitiba: UFPR, 2006.

LEE, Peter. History in the classroom. In How Students Learn. Washington: The national academies press, 2005.

MAGRIS, Claudio. Contradições paralisam a Europa. Entrevista ao Jornal 0 Estado de São Paulo. São Paulo: 0 Estado de São Paulo: 2009; Caderno Cultura, p.6.

MORAES, Maria Célia Marcondes de. Recuo da teoria. In.MORAES, M.C.M. (org.) Iluminismo às Avessas. Produção de conhecimento e políticas de formação docente. Rio de Janeiro: DP\&A, 2003.

OAKESHOTT, Michael. Sobre a Historia. Rio de Janeiro: Topbooks, 2003.

RUSEN, Jorn. Razao Histórica. Brasília: UnB, 2001. 
RUSEN, Jorn. La historia, entre modernidade y postmodernidad. In. New history, nouvelle histoire: hacia una nueva historia. Madrid: Actas, 1993:

SCHMIDT, M.A./ BARCA, I. Aprender historia: perspectivas da educaçao histórica. Ijuí: Unijui, 2009.

SCHMIDT, M.A./ GARCIA, T.M.F.B. 0 trabalho com objetos e as possibilidades de superação do sequiestro da cognição histórica: estudo de caso com crianças das séries iniciais. In. SCHMIDT,M.A./GARCIA, T.M.F.B. (org.) Perspectivas de investigação em Educaçao Histórica. Curitiba: UTFPR, 2007.

\section{Historical literacy: the challenge for historical education in the XXI's century}

\section{ABSTRACT}

This paper attempts to sketch a provisional account of a notion of historical literacy. It draws on some philosophical considerations suggested by among other Lee, Oakeshoot and Rusen. The idea of historical literacy is emerging as linked to the proposal of developing historical consciousness, as Peter Lee argues and this concept is very important to develop historical competences, like historical interpretation and understanding.

Key-words: Historical literacy - Historical education - Historical cognition 